\title{
A história acordada: tempo de ação/tempo de reflexão em Os memoráveis, de Lídia Jorge
}

\author{
Claudia Amorim \\ Universidade do Estado do Rio de Janeiro
}

\begin{abstract}
Resumo
Em Os memoráveis Lídia Jorge volta ao tema da Revolução dos Cravos, revista por três jovens jornalistas que entrevistam as personagens do levante de abril para um documentário para a tevê norteamericana CBS. Dividido em três partes, o romance apresenta a personagem-narradora Ana Machado, que organiza a entrevista. A história dos heróis do levante cruza-se com a história pessoal de Ana, filha do jornalista António Machado, participante dos acontecimentos, e de Rosie Honoré Machado, atriz belga que abandona marido e filha para voltar para o seu país. As diferenças entre as gerações mais novas, que abdicam da história, e os personagens da Revolução, esquecidos na contemporaneidade, ficam evidenciadas nesses tempos de dissolução da história.
\end{abstract}

Palavras-chave: história; Revolução dos Cravos; memória; ficção.

\begin{abstract}
In Os memoráveis Lídia Jorge returns to the theme of the Carnation Revolution, reviewed by three young journalists interviewing the characters of the April uprising for a documentary for CBS. Divided into three parts, the novel features the narrator character Ana Machado, who organizes the interview. The story of the heroes of the uprising intersects with the personal story of Ana, daughter of the journalist António Machado, participant in the events, and Rosie Honoré Machado, a Belgian actress who leaves her husband and daughter to return to her country. The differences between the younger generations, who abdicate the history, and the characters of the Revolution, forgotten in contemporary times, become evident in these times of history's dissolution.
\end{abstract}

Keywords: history; Carnation Revolution; memory; fiction.

Recebido em: $16 / 11 / 19$

Aprovado em: 04/12/19

Desculpem não nos encontrarmos nestas ruas.

Só nasceremos amanhã.

Dos murais de Lisboa

Autora de romances, contos, ensaio, uma peça de teatro, e recentemente de uma obra de poesia, com mais de vinte obras publicadas em Portugal e no exterior, a escritora portuguesa Lídia Jorge manifestou em algum momento o seu desejo de ser uma cronista do tempo que 
passa. Desde $O$ dia dos prodígios (1980), seu romance de estreia, o diálogo com a história recente de Portugal torna-se um processo de criação estética, presente em grande parte de suas narrativas. Visitando a história contemporânea portuguesa a contrapelo, para empregar a conhecida expressão de Walter Benjamin, Lídia Jorge com Os memoráveis (2014) — quarenta anos após a Revolução dos Cravos — volta de modo inovador ao acontecimento histórico que põe fim a quase cinco décadas de ditadura salazarista, dando voz aos protagonistas de Abril.

A escritora abre o seu romance com duas epígrafes que falam da história nas ruas. Destaco uma delas aqui, para mostrar como a história se inscreve na obra de Lídia Jorge desde a sua portada. Abril foi sobretudo um acontecimento histórico que tomou as ruas. As mesmas ruas que serão percorridas pelos jovens jornalistas que se põem a entrevistar alguns dos protagonistas do 25 de Abril, num momento outro da história contemporânea: na era em que alguns defendem a pós-história e nesse momento em que muitos das jovens gerações inscritas na pós-modernidade - esqueceram-se deliberadamente de vinculações entre passado, presente e futuro.

O confronto entre dois tempos - o dos jovens que herdaram o legado da revolução, mas não mais o consideram primordial - e o dos protagonistas da cena de abril, que fizeram a história mas por ela foram esquecidos, se inscreve nesse romance.

Dividido em três partes ("A fábula", "Viagem ao coração da fábula" e "Argumento"), a narrativa tem como personagem principal a jovem jornalista portuguesa Ana Maria Machado, que mora nos Estados Unidos e trabalha como repórter para a cadeia televisiva CBS. Especializada em jornalismo de guerra, Ana é desafiada por Robert (Bob) Peterson e pelo padrinho deste que, como embaixador americano em Lisboa, testemunhou os acontecimentos que se seguiram ao 25 de Abril - a produzir o primeiro documentário de uma série da CBS intitulada "A história em vigília" ou "A história acordada".

A fábula da "metralha das flores" é então assunto de uma conversa entre Miss Machado, Bob Peterson e seu padrinho, numa festa na grande casa do ex-embaixador, às margens do rio Potomac. O padrinho de Bob a estimula a encabeçar esse documentário, a voltar a seu país, do qual estava afastada há muito.

Vá lá, Miss Machado, vá lá, que se procurar bem, verá como ainda encontra, entre as pedras da calçada, o resto daquela metralha. Ouvia o padrinho dizer uma e outra vez. Vá lá e traga alguma coisa boa, alguma coisa limpa, uma narrativa luminosa na qual uma pessoa se reveja. (JORGE, 2014, p. 43)

A princípio relutante em voltar seu olhar para essa fábula antiga e à ideia de retornar a Portugal e encontrar o pai, o jornalista António Machado, com quem Ana não tinha uma boa relação e de quem havia muito se afastara, a jovem assume a tarefa e viaja ao coração da fábula, a fim de cumprir seu trabalho. Em Lisboa, convoca o serviço de dois antigos amigos do tempo 
da universidade: Margarida Lota e Miguel Ângelo, da firma Lota\&Ângelo, associados. Embora inteligentes e perspicazes, seus colegas jornalistas faziam coberturas de festas de casamentos, completamente afastados da vocação de repórteres de guerra a que aspiravam. Incitados pela proposta de Ana, Margarida e Ângelo imediatamente se disponibilizam a buscar um resto da metralha das flores, entre as pedras da calçada, no momento em que têm nas mãos a velha fotografia de um grupo de pessoas em um jantar no restaurante Memories.

A velha fotografia, que o pai guardara na parte superior da estante de casa, além de trazer a cena viva dos dias subsequentes à Revolução de Abril, provoca em Ana a revisão de sua própria história. Nela, além de alguns dos revolucionários, estão o pai da jornalista — António Machado - e a sua mãe belga - Rosie Honoré Machado - , que pouco depois abandonaria filha e companheiro, ocasionando um esfacelamento familiar do qual Ana e António nunca mais se recuperaram, uma vez que o diálogo entre pai e filha havia se tornado impossível. A memória da infância de Ana, de sua convivência com o pai e com Rosie, a quem nunca se refere como mãe, mistura-se à memória dos tempos construídos por aqueles que os tornariam memoráveis não só para a sociedade portuguesa, como para o mundo. Passado e presente. Vida pessoal e História. Nesse entrecruzamento, está Ana, mas ao mesmo tempo a jornalista, distanciada dos fatos, esforça-se para não estar. É como jornalista que procura e encontra a fotografia na casa do pai. É como jornalista que decide iniciar o resgate do passado, tendo na mão a fotografia do Memories.

Assim, é a partir da imagem amarelada e empoeirada, do famoso fotógrafo Tião Dolores, e pertencente a António Machado, que Ana começa a traçar, com os amigos jornalistas, o caminho das entrevistas que farão parte do material a ser produzido para a CBS em 2004, ano em que o levante de abril completaria trinta anos. A fotografia, recolhida por Ana sem que o pai o saiba, estampa, além dos pais de Ana, um grupo de pessoas que protagonizou ou viveu visceralmente o dia 25 de Abril desde as suas primeiras horas. $\mathrm{O}$ grupo assinalado, novos "varões" da história, imortalizado pela fotografia, vive no anonimato dos dias, disperso pelas ruas, distantes dos dias de glória.

Instaura-se desde esse momento o contato desses jovens jornalistas, nascidos no pós25 de Abril, com a história viva, ou, se quisermos, com a história acordada que se escreve no coração da fábula, no momento em que, a partir das entrevistas, a narrativa subjetiva dos entrevistados entra em cena para iluminar novamente um acontecimento mítico de um passado recente da história portuguesa.

Pelos olhos dos jovens jornalistas, o leitor também é convidado a ler esses depoimentos por um novo viés, deparando-se com heróis ícones da Revolução de Abril, envelhecidos, ressentidos, esquecidos. Na fotografia do Memories os heróis do levante serão identificados por alcunhas a eles atribuídas por Rosie Honoré. 
Como observa Isabel Cristina Mateus,

o instantâneo de Tião Dolores (Sebastião Alves) constitui, de algum modo, a "Última Ceia" fotográfica do "dia original": nele estão presentes não apenas os "apóstolos" da revolução, como nele se fixa e oculta um segredo, um momento que a investigação virá revelar ter sido decisivo, também ele memorável, para a viragem no curso da Revolução. Da mesma forma que nele se oculta e, paradoxalmente, dá a ler, a narrativa das origens de Ana Maria, o capítulo inicial da sua (auto)biografia ou nela se reflecte a sombra e o silêncio da relação com o pai, reputado jornalista no meio lisboeta. (2014, s. p.)

A partir das entrevistas que se iniciam com os personagens da fotografia, vislumbram-se as desavenças entre esses heróis, alguns dos quais frequentadores da casa em que Ana vivia com os pais quando criança. Ana, Margarida e Miguel entrevistam, então, o fotógrafo Tião Dolores (Sebastião Alves), identificado como o fotógrafo Eduardo Gageiro, Ernesto Salamida, o Oficial de Bronze (identificado como Vasco Lourenço), El Campeador (identificado como Otelo Saraiva de Carvalho), a viúva de Charlie 8 (identificado como Salgueiro Maia), entre outros.

A memória acionada lança luz sobre um tempo — de ares tantas vezes respirados - e retira-lhe a poeira que encobre e devota ao esquecimento o levante dos capitães de Abril e o decorrer dos dias que se seguiram ao dia levantado e principal. Para os jovens jornalistas, que conheciam alguns dos fatos, mas deles estavam definitivamente distanciados, o passado é iluminado, passado a limpo, ao mesmo tempo que, paradoxalmente, esse passado perde sua aura mítica em razão da clivagem entre o significado profundo dessa Revolução, feita com flores e sem sangue, e o que se lhe seguiu, tempo de dissolução e esquecimento.

No processo da história recente, a utopia revolucionária do 25 de Abril perdeu a luminosidade ímpar de seu tempo, virou uma narrativa antiga e encapsulada num tempo que as novas gerações não viveram. É durante as entrevistas que Ana, Margarida e Miguel se deparam com as sombras dos heróis que, naqueles dias, puseram os ponteiros da história para andar. Envelhecidos, ressentidos, melancólicos, o relato do 25 de Abril por seus protagonistas ainda guarda o encanto inominável do que estava a decorrer, mas apresenta a contrapelo o desencanto ou distopia dos antigos heróis que "vivem o presente como um lugar de exílio, desterrados na névoa da melancolia e da irrealidade que sobre eles o tempo teceu" (MATEUS, 2014, s. p).

O confronto entre os dois tempos (presente e passado) recupera a história possível dos heróis de Abril e torna plausível o rumo de cada um dos entrevistados. Interessante observar que é justamente na parte intitulada "Viagem ao coração da fábula", portanto da narrativa, que os acontecimentos relatados pelos heróis da Revolução dialogam mais estreitamente com a história.

Em artigo intitulado "Entre o sono e a vigília" (1998), o filósofo José Américo Motta Pessanha pergunta-se de início onde está a fronteira, se é que existe, entre a história e a ficção. Algumas narrativas, como a que se analisa, esbatem nitidamente esses tênues limites. É justamente no coração da fábula, na qual adentram os jornalistas, que a ficção ilumina a história. 
Os depoimentos dos personagens históricos — os “apóstolos” da Revolução —, malgrado o teor melancólico que apresentam, humanizam os personagens históricos que nos anos subsequentes à Revolução sofreram revezes, foram traídos e viveram dissabores. Contudo, em seus relatos, não se colocam como vítimas, mas como atores dessa história que, segundo o depoimento do Oficial de Bronze (Vasco Lourenço), constituiu-se num milagre:

Milagre, sim. Sendo eu um agnóstico, até que gostaria de usar outro termo mais sereno, mas não encontro. E milagre porquê? Pela coincidência no tempo de tantos factos inesperados. Olhai. Registem a minha opinião antes que seja tarde. (JORGE, 2014, p. 96)

Os depoimentos dos protagonistas daquele tempo sublinham a importância da vigília que, à época, sustentou os fatos inesperados, possibilitando a sua permanência. Somente a vigília, esse estado de prontidão, essa necessidade de estar desperto, foi capaz de acabar com o sono torturante do salazarismo. Somente a vigília foi capaz de manter, pelo menos por um tempo, a história acordada.

Contudo, o que regularmente se vê, após os grandes acontecimentos, é que, passados os momentos iniciais, a vigília cede lugar ao sono ou à apatia. A história iluminada se cristaliza em passado, os protagonistas da cena revolucionária permanecem no interior das fotografias empoeiradas, enquanto os homens de carne e osso inserem-se nos dias iguais, nos quais a poeira se sobrepõe a tudo. Nesses momentos, indaga-se se é possível o espírito da revolução permanecer eternamente, como chama que nunca apaga, sempre vigilante, sem que se deixe vencer pela acomodação.

Como já observara Ana Machado, em sua atividade de repórter de guerra no deserto, "na poeira se encontram livros inteiros" (JORGE, 2014, p. 59). Poeira, ruína, escombro. O passado enaltecido, mas esquecido, transformado em pó, ruína de um tempo, escombro.

Aludindo a Walter Benjamin, é para os escombros, para as ruínas que os anjos da história parecem olhar. A melancolia do presente reside no fato de que só resta ao anjo da história contemplar o passado em ruínas. $\mathrm{O}$ anjo contempla o passado, horroriza-se com o que vê e torna-se melancólico. Consequentemente, permanece estático.

Em seu estudo "Teses sobre a filosofia da História" o filósofo da Escola de Frankfurt destaca que "articular historicamente algo passado não significa reconhecê-lo "como ele efetivamente foi'. Significa captar uma lembrança como ela fulgura num instante de perigo" (BENJAMIN, 1985, p. 156).

No mesmo ensaio Benjamin, ao fazer alusão a um quadro de Paul Klee, intitulado Angelus Novus, refere-se à figura do anjo que, no quadro, tem os olhos arregalados, a boca aberta e as asas prontas para voar. Analisando a imagem, Benjamin destaca: 
o Anjo da História deve parecer assim. Ele tem o rosto voltado para o passado. Onde diante de nós aparece uma série de eventos, ele vê uma catástrofe única, que sem cessar acumula escombros sobre escombros, arremessando-os diante dos seus pés. Ele bem que gostaria de poder parar, de acordar os mortos e de reconstruir o destruído. Mas uma tempestade sopra do Paraíso, aninhando-se em suas asas, e ela é tão forte que ele não consegue mais cerrá-las. Essa tempestade impele-o incessantemente para o futuro, ao qual ele dá as costas, enquanto o monte de escombros cresce ante ele até o céu. Aquilo que chamamos de Progresso é essa tempestade. (BENJAMIN, 1985, p. 158-159)

Em Os memoráveis há diversas passagens em que Ana Machado e Bob Peterson ou mesmo seu padrinho destacam o contraste entre o anjo da história e o anjo da harmonia. A própria Ana o lembra em determinado momento:

A figura do padrinho insinuando um momento de excepção, um momento em que o anjo da harmonia contrariava os terríveis anjos da história, anjo da beleza e da bondade, que produzia de vez em quando o milagre do concerto, como ele havia dito, tinha-me convencido a tomar sobre os ombros a missão de recuperar breves momentos vividos pelo colectivo de uma nação, e eu procurava fazer o meu trabalho. (JORGE, 2014, p. 266)

Ao buscar o momento iluminado, concertado pela coletividade, tem-se como fito acordar a história. A história acordada — portanto — torna-se um fator de movimento. É preciso resgatar o momento luminoso, que fará novamente despertar a partir do presente a prontidão da vigilância.

É pelo depoimento dos envolvidos no coração da fábula que a história - expulsando a melancolia do cotidiano e do banal - reacende o momento luminoso do anjo da harmonia, contaminando as jovens gerações. Ana, Margarida e Miguel Ângelo, cada qual a seu modo, adentram na história, em seu momento iluminado, veem seus descaminhos, percebem o contraste entre o passado recente e o presente no qual os heróis da Revolução são meras sombras de si mesmos. Retirá-los das sombras da história torna-se uma tarefa para esses jovens, não movidos apenas pelo "vil metal".

Um encontro em especial marca uma modificação na percepção de Ana. Após o encontro dos jovens com El Campeador, que se encontra envelhecido, mas montado em um cavalo, em posição de guarda, Ana retorna à casa do pai e reflete:

Como descrever o que se passou depois de termos regressado do encontro com El Campeador? Como explicar os meus pensamentos avulsos, os meus gestos prescindíveis? Tal como disse, os meus colegas de equipa voltaram impressionados com a destreza de El Campeador sobre a montada, e eu mesma não conseguia libertarme daquela paisagem brumosa, daquelas ondas, daquele encontro sobre a areia, muito menos da jactância daquelas réplicas produzidas a partir da garupa do cavalo. [...] Fiquei a ver António Machado e a pensar que a alcunha de El Campeador que Rosie Honoré havia atribuído ao oficial que participava do jantar do Memories, de braços cruzados, a olhar para longe, Cuba, Tirana ou Trípoli, tinha a sua razão de ser, e 
baseava-se na percepção que ele mesmo alimentava sobre o seu próprio desempenho. Fiquei a pensar que essa dimensão não era trágica, nem cômica, nem melodramática, apenas lírica, e que passados todos esses anos, aquele homem dormia sobre o cavalo, da mesma forma que o meu pai dormitava à secretária. (JORGE, 2014, p. 225-226)

Como o pai, El Campeador era a seu modo um vigilante na história. O que poderia se tornar algo cômico ou trágico ou mesmo melodramático, era afinal algo um tanto lírico e isolado, num tempo pouco afeito a lirismos. Retirar do isolamento o que se esconde no passado é novamente acendê-lo, iluminá-lo.

Essa é a compreensão de Ana, quando escreve o argumento do documentário que deve ser o guia do primeiro episódio da série chamada "A história acordada":

[...] obedecendo ao princípio de que, de vez em quando, uma entidade luminosa dribla os anjos da tragicomédia contínua, o silêncio deve ser interrompido pelo som das passadas que iniciam a canção cante, na noite de vinte e cinco do quatro, de mil novecentos e setenta e quatro. (JORGE, 2014, p. 331)

A jornalista Ana Maria Machado e seus jovens colegas perspectivam nessas entrevistas não só o tempo da utopia, como o tempo da desilusão, assim como se aproximam de narrativas esquecidas ou desconhecidas pelas novas gerações que se distanciaram do cerne dos acontecimentos. Em tempos de pós-verdades, de distopias de toda ordem, resgatar o momento luminoso é voltar ao coração da fábula, é talvez fazer andar novamente os ponteiros do relógio, em consonância com o relato que Charlie 8 (Salgueiro Maia), pela voz de sua viúva, faz do 25 de Abril:

Contou o meu marido que ao dar a volta ao Rossio, quando as tropas de Infantaria 1 se renderam em frente ao Teatro Nacional, ele dava corda ao relógio e começava a ouvi-lo trabalhar. Tanque tanque, tanque tanque. Dizia que as horas do relógio tinham começado a bater dentro da sua cabeça. Dizia ele que sabia que cinco mil homens, naquele momento, estavam a fazer rodar as agulhas sobre o mostrador. (JORGE, 2014, p. 335)

José Américo Motta Pessanha, no mesmo artigo anteriormente referido, recorre à mitologia para mostrar a luminosidade da história, da memória e do tempo, na ordenação do mundo antes do Olimpo. Observa o filósofo que Mnemosine (Memória) é irmã do Titã Cronos (pai de Zeus). Memória e Tempo (Mnemosine e Cronos) são gerados por Gaia, a Terra, e Uranos (os céus). Assim, como os deuses do Olimpo nos mostram, no início da ordem do mundo estão a memória e o tempo. Filha de Mnemosine, Clio (musa da História) também participa desse momento de ordenação.

Nesse sentido, o desejo da escritora de ser uma cronista do tempo passado ou de pôr em crônica os acontecimentos, como o fez Fernão Lopes, não tem outro fito do que tirar a poeira 
dos acontecimentos e iluminá-los, a exemplo da "entidade luminosa que há muito que tinha feito o seu trabalho e, cansada, havia batido as asas em retirada, deixando-nos atrás de si vinte, trinta, quarenta, cem anos, ou o tempo que ainda venha a ser necessário, para decifrarmos o que verdadeiramente se passou" (JORGE, 2014, p. 342).

Contudo, pela óptica das novas gerações, o argumento de Ana Machado, ao final, feito para a CBS, rede norte-americana, não nos esqueçamos, a partir de uma proposta de criar uma narrativa histórica acordada (feita em acordo), o momento iluminado destina-se ao encapsulamento, devendo, portanto, ficar no passado. Cabe, então, ao leitor decidir se o que se ilumina é fagulha para novos e necessários incêndios ou se é clarão acordado e dominado.

\section{Referências}

BENJAMIN, Walter. Teses sobre a filosofia da História. In: KHOTE, Flávio; FERNANDES, Florestan (orgs.). Sociologia. São Paulo: Ática, 1985.

JORGE, Lídia. Os memoráveis. 4. ed. Lisboa: Dom Quixote, 2014.

MATEUS, Isabel Cristina. Recensão crítica da obra de: JORGE, Lídia. Os memoráveis. 4. ed. Lisboa: Dom Quixote, 2014, Revista Diacrítica, Braga, v. 28, n. 3, 2014. Disponível em: http:// www.scielo.mec.pt/scielo.php?script=sci_arttext\&pid=S0807-89672014000300025. Acesso em: 13 jun. 2017.

PESSANHA, José Américo Motta. História e ficção: entre o sono e a vigília. In: RIEDEL, Dirce Cortes (org.). Narrativa, ficção e história. Rio de Janeiro: Imago, 1998.

\section{Minicurrículo}

Cláudia Amorim possui graduação em Português-Literaturas de Língua Portuguesa pela Universidade Federal do Rio de Janeiro (1988), especialização em Literatura Portuguesa pela Universidade Federal do Rio de Janeiro (1989), mestrado em Literatura Portuguesa pela Universidade Federal do Rio de Janeiro (1995), doutorado em Literatura Comparada pela Universidade do Estado do Rio de Janeiro (2006) e pós-doutorado em Literaturas Africanas de Língua Portuguesa pela Universidade de São Paulo (2012). Atualmente, é professora adjunta da Universidade do Estado do Rio de Janeiro, atuando na graduação e na pós-graduação. Tem experiência na área de Letras, com ênfase em Outras Literaturas Vernáculas, principalmente em literatura portuguesa contemporânea e literaturas africanas contemporâneas em língua portuguesa. Publicou recentemente em coautoria com Maria Paladino a segunda edição revista e ampliada (2019) de Cultura e literatura africana e indígena, pela IESDE Brasil, além de artigos em revistas especializadas. 